\title{
ENTReVISTADORes
}

MARIA IRENE DE Q. F. SZMRECSANYI Cientista social, doutora em sociologia. Professora de Fundamentos Sociais da Arquitetura e do Urbanismo, representante do AUH na CPG da FAUUSP, coordenadora do convênio para o mestrado interinstitucional da FAUUSP e Universidade Estadual de Londrina - UEL. Autora de Educação e fecundidade: Ideologia, teoria e método na sociologia da reprodução humana (Hucitec, 1986), Rio e São Paulo: Raízes da substituição da metrópole nacional (Revista USP, n. 17 1993), Catálogo da Exposição Cidades Jardins: A busca do equilíbrio social e ambiental, 1888-1998 (Fundação Bienal de São Paulo, 1997). Diretora da coleção Arte e Vida Urbana, Editora Hucitec (desde 1993). Editora chefe da POS - Revista do Programa de Pós-Graduação em Arquitetura e Urbanismo da FAUUSP. 


\section{JORGE HAJIME OSEKI}

Arquiteto e urbanista, doutor em arquitetura, professor de Tecnologia da Arquitetura, orientador na pósgraduação. Autor de 0 único e 0 homogêneo na produção do espaço. In: MARTINS, José de Souza (org.). Henri Lefèvre e o retorno à dialética (Hucitec, 1992) e do vídeo As margens do Rio (NAPPLAC, FAUUSP, 1993). Membro da comissão editorial da POS - Revista do Progama de Pós-Graduação em Arquitetura e Urbanismo da FAUUSP.

\section{WILSON EDSON JORGE}

Arquiteto e urbanista, professor livredocente de Planejamento Urbano e Regional, orientador na pós-graduação, vice-presidente e representante do Departamento de Projeto na CPG da FAUUSP. Entre os seus projetos: coordenação de plano para a região TietêParaná e casas de detenção para o sistema penitenciário para o estado de São Paulo (2000). Co-autor de Hotel: Planejamento e projeto (Senac, 2000). Membro da comissāo editorial da revista POS - Revista do Programa de Pós-Graduação em Arquitetura e Urbanismo da FAUUSP. 


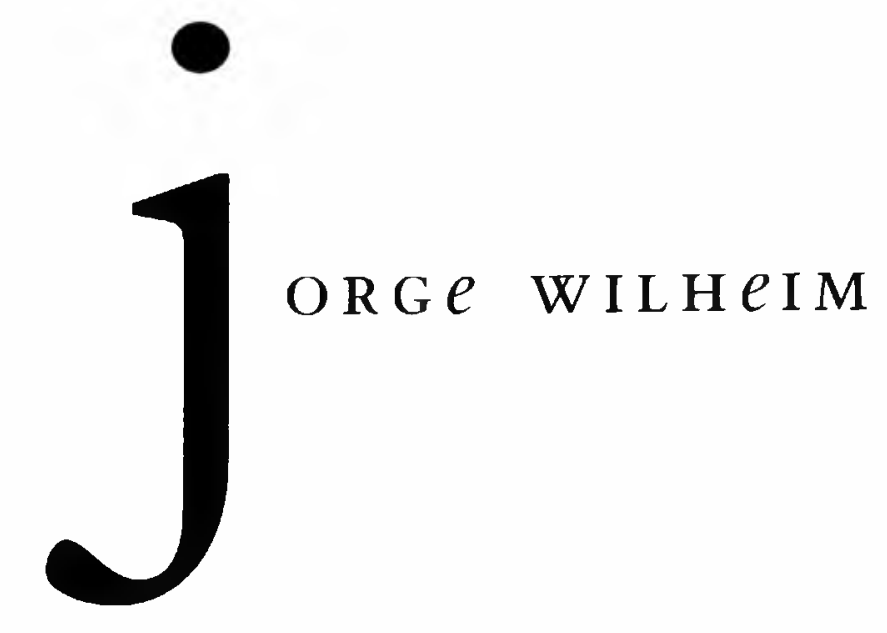

Nascido na Itália (1928), chegou em São Paulo aos 10 anos, formou-se em arquitetura (1952) pelo Mackenzie. Abriu seu escritório no ano seguinte, ao vencer um concurso para o projeto de um hospital, a Santa Casa de Jaú. Classificou-se com sua equipe em outros concursos: Clube dos Artistas (1952), Paço Municipal de Campinas (1957), Clube Paulistano (1958), Assembléia Legislativa do Rio Grande do Sul (1958), late Clube de Londrina (1958), sede do Jockey Club (1959), Hotel Guarujá (1961), Ópera de Belgrado (1973), reurbanização do Anhangabaú (1981), Revitalização do Centro (1996).

Participou em 1963-1964 da montagem de nova universidade federal em São Paulo e iniciou-se no magistério, tendo ambas as atividades sido compulsoriamente interrompidas por motivos políticos pela movimento civil-militar de 1964. Entre os projetos arquitetônicos, o de maior complexidade foi o do Parque Anhembi, projetado e construído de 1969 a 1974, com pavilhāo de exposições, estrutura erguida do solo em 8 horas, o hotel e a arcada de lojas ainda aguardando ultimação. Destacam-se também os projetos das segunda e terceira fases do Hospital Albert Einstein, a sede da Fapesp, o ginásio Senai, a sede do Clube Hebraica, uma sede da Cesp, além de numerosos edifícios de apartamentos, de escritórios e algumas residências.
Iniciou-se em urbanismo em 1954, ao planejar Angélica, nova cidade pioneira em Mato Grosso do Sul. Participou em 1956 do concurso nacional de Brasilia, liderou a equipe que formulou o plano básico de Curitiba (1965), de Joinville (1965), Osasco (1966), Natal (1967), Guarulhos (1969), Fortaleza (1969), Campinas (1969), Goiânia (1988), São José dos Campos (1989), Paulínia (1989) e o terminado plano estratégico de Campos do Jordão (2000). Projetou, ainda, a Cidade Industrial de Curitiba (1973), os clubes e residências de "Terras Altas" aos pés da Serra da Cantareira (1994) e a Cidade Industrial de Londrina (1997).

No campo do desenho urbano, projetou o Pátio do Colégio, o Vale do Anhangabaú, a Nova Augusta, a Nova Paulista e a "árvore 4 vilas" Outros projetos de alcance para a vida urbana foram os primeiros postos automobilisticos cobertos e seu "minishopping" (Shell, 1962), a utilização do álcool como combustivel (1976), a co-geração de energia por trocadores de calor (1981) e os estudos para otimização de coletores solares (1982). Elaborou, com equipe, para o Instituto Florestan Fernandes, 0 estudo "Intervenções na paisagem urbana de Sāo Paulo"

Foi secretário estadual de Economia e Planejamento (1975-1979, governo Paulo Egydio Martins), secretário municipal de Planejamento (1983-1985, prefeito Mário Covas), Presidente da Fundação 


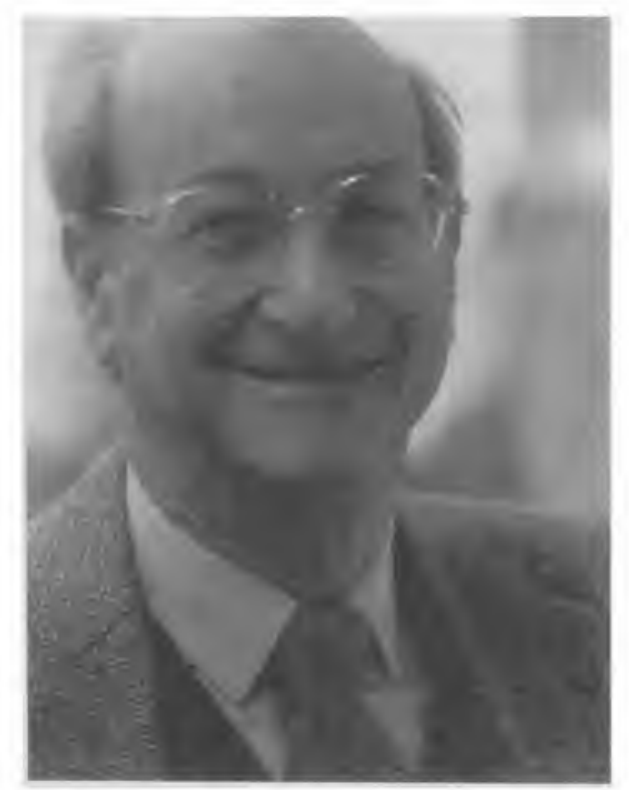

Bienal de São Paulo (1986-1987), secretário do Meio Ambiente (1987-1991, governador Quércia) e presidente da Emplasa (1991-1994). Nesses postos teve a oportunidade de criar e implantar: o Procon, a Fundação Seade, a EMTU, o Passe do Trabalhador (hoje conhecido por vale-transporte), o Passe do Idoso, o cadastro de árvores significativas, 0 Programa "Feito em Casa" o Cadastro de Referências Urbanas, o manual contendo padrões de urbanização, o Plano Diretor de São Paulo (19852000), os programas ambientais Olho Verde, Mata Fogo, Alerta Contra poluição, Praia Limpa e o reflorestamento aéreo da Serra do Mar, o Parque Ecológico de Campinas, o início de implantação do Parque da Juréia. Para a região metropolitana coordenou a montagem do "Plano de defesa civil para periodos de chuvas excessivas" e dirigiu a elaboração do plano metropolitano da Grande São Paulo (1994-2010).

Convidado pelas Nações Unidas e nomeado secretário-geral adjunto, concebeu, articulou e realizou a Conferência Hábitat 2 de Istambul (1996), sobre o futuro das cidades, tendo para esse fim se deslocado para Nairobi (Quênia), sede da agência Hábitat da ONU (1994-1996); propôs a reestruturação do centro das Nações Unidas para os assentamentos humanos. Foi consultor contratado para a reformulação do texto da Lei do Plano Diretor de São Paulo (1998). Foi responsável pelo capítulo sobre questões urbanas do relatório das Nações Unidas sobre o desenvolvimento urbano (PNDUD, Brasil, 1998) e pelo capitulo Cidades sustentáveis que integra o estudo do IBAM para a Agenda 21 (1999).

Além de inúmeros artigos para jornais, tem oito livros publicados, alguns traduzidos, o último lançado em junho de 1998: O caminho de Istambul, com seu apêndice Nosso fecundo fim-de-mundo. Este último foi lançado, com o título Overcoming the traumatic transition, pelo Woodrow Wilson Center de Whashington (1999). Nos próximos meses será publicado o livro Tênue esperança no vasto caos, em que analisa as perspectivas do próximo século e lança a hipótese de um novo ciclo humanista. Foi membro do Conselho de Reforma do Estado (1998-1999). Conferencista e consultor de órgãos nacionais e internacionais. Consultor Sebrae para questões metropolitanas. É membro do Instituto de Estudos Avançados da USP (área assuntos internacionais), do Conselho Interdisciplinar de Segurança, dos conselhos administrativos do Museu Lasar Segall, do Instituto de Arte Contemporânea e da Fundação Nemirowski; foi eleito presidente do Conselho Administrativo da Fundação Bienal (2000/ 2003).

Em 2001 assumiu, pela segunda vez, o cargo de secretário de Planejamento e Urbanismo do Municipio de São Paulo (gestão Marta Suplicy). 
Jorge Oseki: Nos últimos decênios dois paradigmas dominaram os conceitos de planejamento urbano: de um lado, o planejamento estratégico, de outro lado, o planejamento participativo. Há lugar para o primeiro numa gestão em que se valoriza a participação? Pergunto ainda: como pode ser concebido o planejamento ambiental em São Paulo?

Wilson Jorge: Qual a importância da pesquisa de pós-graduação em face dos problemas de uma cidade como São Paulo? Como deveriam se orientar as relações universidade-prefeitura?

Maria Irene Szmrecsanyi: Complementando os demais, gostaria de afirmar o interesse em ouvi-lo sobre estas questões a partir de sua experiência local, em São Paulo e em outras partes do Brasil e também daquela que obteve a partir de Nairobi, ou seja, sua atual visão mundial das cidades, em especial das cidades ditas subdesenvolvidas. Por outro lado, indago como será possivel planejar São Paulo do âmbito municipal, já que o fenômeno urbano São Paulo vai muito além das fronteiras do municipio.

Jorge Wilheim: A nova gestão, liderada por Marta Suplicy, caracteriza-se por diversos aspectos que são importantes do ponto de vista político, da práxis do planejamento. Um deles é o fato de hoje existir planejamento. Parece absurdo ter que afirmá-lo, mas a verdade é que nas gestões anteriores não existia, tanto que a Sempla teve sete secretários em oito anos, o que revela a pouca importância que a cúpula municipal dava ao setor de planejamento, nada Ihe solicitando.

$\mathrm{Na}$ orientação geral, dada pela prefeita, foi salientado, em primeiro lugar, que não haveriam grandes modificações estruturais, mas haveria grande modificação de gestão, não partindo para a criação de grandes alterações na estrutura da administração. Há apenas duas secretarias que se fundem na Infra-Estrutura: Vias Públicas e Obras. E os programas de inclusão social acabarão gerando uma Secretaria do Trabalho e Solidariedade. Há, no entanto, uma alteração grande que vai ser construída nesses quatro anos: a descentralização em subprefeituras, na qual a Secretaria de Administração Regional terá o nome de Secretaria de Implantação de Subprefeituras. Mas a gestão mudou radicalmente. A prefeita nos solicitou uma atuação sinérgica. As secretarias de Habitação, de Infra-Estrutura, de Transportes, de Meio Ambiente e de Planejamento constituem um grupo que tem de maximizar a sua informação interna e o seu trabalho de conjunto. As secretarias que trabalham socialmente: Educação, Assistência Social e Saúde, às quais se acrescentará a futura Secretaria de Trabalho, funcionam como outro grupo que deve trabalhar em conjunto. Não se elimina tudo aquilo que é individual e que do ponto de vista administrativo é próprio a cada uma das unidades. Mas a gestão tem que ser sinérgica e esta é uma alteração que possivelmente dará frutos a curto prazo.

Planejamento, aqui, tem também uma importância estratégica. A cidade tem que ser vista dentro de uma metrópole e de um mundo em que a conectividade global acelerou todos os processos de mudança. Não mais podemos entender São Paulo sem pensar nos seus vínculos metropolitanos e sem pensar na sua relação com o resto do mundo e sua economia urbana também vinculada com o mundo. Este ambiente da globalização, em que devemos manejar oportunidades e riscos, a fim de estabelecer uma estratégia de desenvolvimento, é que nos interessa.

O planejamento adquire por isso uma presença não digo importância, mas uma presença - na administração, no governo municipal, que não tinha. Eu insisto em dizer que não é um problema de importância - é muito difícil dizer que tenha mais importância que o problema da saúde - mas presença sim, porque nós temos que pensar em tempos: médio prazo, longo prazo. Temos que pensar em espaços metropolitanos, latinoamericanos, mundial. E temos que pensar na interação dos diversos setores, que é aquela alteração de gestão que antes mencionei. 
Perguntaram-me se o planejamento será estratégico ou participativo. Eu não consigo entender a palavra "ou" porque não há uma necessária diferenciação entre planejamento estratégico e planejamento participativo. A participação democrática não só é um problema político da maior importância para o desenvolvimento, como é também, na sua práxis, uma pedagogia. Além do exercício de um direito, a participação dos cidadãos se transforma numa pedagogia, uma vez que até mesmo na elaboração de um orçamento participativo eles têm que se confrontar com problemas que não são individuais, mas que são também dos outros; não só com problemas das suas ruas, mas de seu bairro; com problemas que não são só de seu bairro, mas da cidade. É nisso que reside o caráter pedagógico da participação dentro das práticas utilizadas em diversas cidades e que o serão também em São Paulo. Por outro lado, o orçamento participativo adquire um efeito prático porque por meio dele se definem prioridades em obras e serviços em cada subprefeitura, o que significa o reforço dos conselhos a serem criados em cada subprefeitura e assim por diante. É, portanto, uma prática que respeita os direitos dos cidadãos e os coloca a trabalhar pela cidade. Os aspectos do planejamento estratégico são um desdobramento muito natural das práticas de planejamento, que deixaram de ser tão formais quanto eram no modernismo para serem mais entrosadas com os objetivos do desenvolvimento. Este não é apenas crescimento, mas é aquilo que as Nações Unidas chamam de desenvolvimento humano, indicando que não se trata apenas do crescimento da economia. Embora seja importante o crescimento da economia, o desenvolvimento é, na realidade, o avanço de uma sociedade na direção de um objetivo que é socialmente colocado: uma sociedade mais justa, um nível de vida melhor, com exclusão menor ou inexistente. E nisso, também, existe muita clareza na orientação política da prefeita, no sentido de que o seu terá que ser um governo de inclusão.
Portanto, a preocupação social deverá ser dominante nas decisões políticas do governo municipal. É onde entra a palavra, o adjetivo "estratégico" apenso a planejamento. Muitas vezes nós inventamos adjetivos para a palavra planejamento porque há necessidade de distinguir uma prática de outras práticas anteriormente adotadas. Vocês se lembram que planejamento e plano já tiveram muitos adjetivos: desenvolvimento integrado, sustentável, estratégico...

\section{MI: Era burocrático?}

JW: Isso nós planejadores nunca admitimos (risos). Éramos burocráticos sim, mas de qualquer forma, em muitas ocasiões, havia adjetivos e eu costumava dizer algo que repito: esses adjetivos são esclarecedores, porém circunstanciais. Objetivam naquele momento separar o trigo do joio, ou indicar a orientação, dar as tarefas de planejamento. Mas uma vez superado aquele momento, aquela circunstância, o adjetivo cai ou é substituído por outro, enquanto o substantivo continua a ser planejamento. O mesmo ocorre na questão do desenvolvimento.

JO: É o título do seu livro?

JW: Sim! No livro $O$ adjetivo e o substantivo, que é da década de 70, eu já me referia a isso. Com relação ao desenvolvimento, inventou-se a palavra sustentável, adjetivo útil, mas na minha opinião, se não for sustentável não é mais desenvolvimento e se não for humano, muito menos! Então, são adjetivos que corrigem as práticas, mas não podemos esquecer que se trata de adjetivos e que os substantivos são planejamento e desenvolvimento.

Essa observação parece-me pertinente quando nós pensamos no dilema da relação entre planejamento e ambiente. Em primeiro lugar, devo dizer que costumo falar de ambiente e não de meio ambiente. Há um problema semântico, acho que meio e ambiente são sinônimos e por mais que quiséssemos dar ênfase ao tema, não há razão para essa redundância. Em segundo lugar, não consigo entender planejamento separado de 
ambiente. Estou me referindo ao planejamento urbano que se apóia em grande parte nos aspectos físicos. Os aspectos físicos do planejamento urbano lidam com o ambiente. Nós podemos pensar em questões ambientais extraurbanas, é claro, temos toda a Amazônia, todo problema da biodiversidade a nos lembrar disso, mas quando tratamos de planejamento urbano não dá para distingui-lo do ambiente. Em termos práticos, que finalmente não resultaram tão práticos assim, também achava que as secretarias de meio ambiente não tinham sentido, que se devia levar toda problemática ambiental para o cerne do planejamento. Mas dadas as

metas dos movimentos ambientalistas de verem reconhecidas e institucionalizadas posições próprias, com nome próprio, inseridas nas estruturas governamentais, a tese de juntar planejamento e ambiente foi muito resistida e não estou mais me batendo por essa bandeira. Acho, inclusive, que o fato de hoje a Secretaría do Verde e Meio Ambiente estar nas boas mãos da Stela Goldenstein, garante, não só que a secretaria vá bem, mas também um entrosamento muito positivo entre o setor ambiental e o setor de planejamento na prefeitura de São Paulo. Eu dizia que o aspecto físico do planejamento urbano percorreu todos os caminhos do setor ambiental. Isso também é verdade, quando nos referimos a algo que levantei só recentemente: 0 problema da paisagem. Os conceitos de paisagem desenvolvidos no ano passado, a pedido da candidata Marta Suplicy se traduziram em um trabalho feito para o Instituto Florestan Fernandes denominado "Intervençōes na paisagem urbana de São Paulo"

Quando Marta Suplicy me encomendou esse trabalho - feito com uma equipe e entregue em meados do ano passado - ela se referia às nossas conversas sobre este assunto como Projeto Belezura e a verdade é que a expressão pegou. 0 tema calou profundamente em diversos setores da população que enxergam o embelezamento da cidade como algo muito positivo, tornou-se um tema mobilizador, importante para a vida cotidiana. Ninguém questiona se é mais importante a belezura ou o combate à pobreza, pois ninguém os trata como temas mutuamente excludentes. Ninguém diz que a beleza da cidade é mais prioritária do que a educação. É claro que não. A verdade é que todo cidadão preza a beleza do ambiente; e a percepção do ambiente, que é a paisagem. No fim da gestão anterior, essa percepção era deprimente, pelo abandono a que foi relegada a cidade: feia, com prédios pichados e em decadência. A população quer contrapor a isso uma cidade limpa, bonita, com mais verde, mais agradável e isso tem muita importância, pois essa é a paisagem que introjetamos toda vez que percorremos a cidade. Introjetamos coisas feias, objetos ruins. Isto não é pouco importante do ponto de vista psicológico.

Entre os problemas que o planejamento enfrenta e que serão traduzidos por diversos instrumentos que mencionarei logo mais, surge uma pergunta freqüente: como resolver tantos problemas, quando a cidade tem tantas dividas e não tem recursos? Acho esta visão muito estreita. Primeiro, o orçamento de São Paulo de longe não é um orçamento pequeno. É o quarto orçamento do país! É muito dinheiro! Se foi bem empregado é outro problema: se existe uma situação de divida, legado do passado, a ser posto em ordem, é outro caso. Mas temos que entender que a cidade é um organismo vivo e, no caso de São Paulo, com uma potencialidade fantástica. Você abre a janela, olha e pergunta: quem fez essa cidade? Não foi a prefeitura. Esta tem atribuições especificas, da maior importância política e mesmo de orientação, por meio de algumas obras públicas e da lei, mas quem construiu tudo isso que está fora foi uma infinidade de pessoas, de empresas, que privadamente lutam para ganhar a sua vida ou para ganhar muito mais que sua vida e acabou construindo uma cidade de enorme dinamismo e de muita energia. Isso não pode ser esquecido quando se pensa na cidade de São Paulo. São Paulo é mais do que a prefeitura! $E$ a solução de 
seus problemas deverá utilizar recursos outros, além dos da prefeitura: os recursos da cidade. É assim que vemos o momento de hoje e a perspectiva de resolver os problemas. Este será um governo de parcerias, não apenas porque esta é uma visão correta e até pragmática, mas porque reconhece; quem faz a cidade, dentro do conjunto de atores, a prefeitura, o setor estatal, terá uma posição absolutamente clara, da qual não se abre mão, com iniciativa e autoridade. Porém, criando condições para parceiros que somem recursos e criatividade.

Por outro lado, vejo também a cidade não apenas como solo, de onde resulta o zoneamento, mas também os seus espaços aéreo e subterrâneo. Isto é importante de assim ser conceituado porque grande parte não só de paisagens como das atividades realizam seu potencial econômico pelo uso do espaço aéreo. Nós estamos começando, inclusive, a ter atividades econômicas utilizando o espaço público subterrâneo. Em que medida, como gestores urbanos ou como planejadores temos tido no Brasil uma visão completa do que é a cidade nos seus recursos? Acho que ainda de uma forma insuficiente. Há no Brasil mais cidades com leis de zoneamento do que com planos diretores. Antes de saber o que fazer com a cidade estamos regulando o que se pode ou não se pode fazer nos lotes privados. A visão privada do espaço urbano marca nossa história desde as capitanias hereditárias, o primeiro macroloteamento realizado no país. Procuraremos rever a lei do zoneamento e o que é construído em lote privado, a partir do espaço público. E procuraremos, não sei se vamos consegui-lo, sempre pautar o desenvolvimento urbano a partir de uma reconquista do espaço público, a qual queremos entender como um espaço de todos e não uma terra de ninguém.

Na medida do possível, vamos procurar interromper esta lesiva tendência de fazer de São Paulo uma aglomerado de condomínios fechados, que se ligam por um sistema de vias públicas, um edifício privado a outro edifício privado, trajeto percorrido com medo. Esta visão é uma tendência existente, mas se perpetuada, se nada fizermos no sentido oposto, nos levará a uma cidade muito mais próxima de "Bladerunner" do que de "Shangrilá" Mais infernal do que paradisíaca.

MI: Bem, mas esse problema não é só um problema de planejamento, é um problema muito mais amplo. E um problema que inclusive transcende a prefeitura. É um problema federal, internacional, essa questão da segurança. Há condições de atuar sobre ele na esfera do planejamento municipal?

JW: Na atual gestão, o conceito que temos do papel da prefeitura é o seguinte: tudo o que acontece aos cidadãos desta cidade concerne à prefeitura, seja aquilo sobre o qual age apenas o governo federal ou o Banco Mundial, seja aquilo sobre o qual age uma organização nãogovernamental do bairro da Mooca. Tudo concerne, embora nem tudo seja ação direta. Não concordo que sobre esse problema de reconquista do espaço urbano do planejamento não haja condições de ação ou de ação direta. Há sim. A segurança é um dos motivos pelos quais o espaço público tem que ser reconquistado e utilizado por todos. Quando nele a autoridade da prefeitura está ausente, alguém, outro, toma conta dele. É aí que ele fica perigoso... Por isso, do ponto de vista da segurança é sumamente importante reconquistar o espaço urbano.

Pretendemos para tal fim utilizar instrumentos relativamente novos. Em primeiro lugar, um plano diretor de caráter estratégico. Um plano diretor que tenha metas de longo prazo e de médio prazo, duas gestões, dez anos, que tenha um horizonte não imediato, mas também não tão afastado, que as projeções sejam feitas com graves riscos de erros. E dentro desse horizonte mais largo estabeleceremos um horizonte imediato, que é o da atual gestão, dentro do qual elaboraremos a "estratégia de desenvolvimento" O plano diretor terá duas partes. Uma primeira parte que reúne diretrizes e a estratégia da atual gestão, abrangendo não apenas o aspecto físico, mas 
também as grandes diretrizes da educação, da saúde, assim por diante. E uma segunda parte, que é claramente física, pois essa parte física tem uma presença grande e requer um planejamento que defina quais são os corredores, as articulações entre os bairros, a forma pela qual se adensa ou se deixa de adensar, a localização de operações urbanas e de áreas de interesse social, a distribuição das áreas verdes.

Quais são os instrumentos que nós pensamos usar? Primeiro, um instrumento já citado: as parcerias público-privadas, importantes inclusive, para captar recursos privados e públicos, porém não-estatais. Embora qualquer cidadão, qualquer empresa, qualquer organização não-estatal possa fazer propostas, a prefeitura pretende tomar iniciativas e conduzir as parcerias.
Esta recuperação da capacidade de iniciativa se fará por meio de um segundo instrumento: as operações urbanas. Cada operação urbana é uma lei. Portanto, exige um programa e um projeto. Depois de elaborado e de aprovado em colegiado ligado à Sempla, vai para a Câmara e finalmente acaba sendo lei.

As operações urbanas voltam a ter o conceito que tinham quando foram criadas no plano diretor, quando eu era secretário do Planejamento do prefeito Covas. Naquela ocasião, vocês se lembram, o plano foi muito discutido em inúmeras reuniões, mas não chegou a ser discutido na Câmara. Ele foi arquivado e retirado por Jânio Quadros tempos depois. A Operação Urbana é uma maneira de projetar setores da cidade, de eventualmente rever o seu adensamento, criar novas centralidades e o seu ambiente. Hoje existem três operações urbanas aprovadas por lei: Operação Faria Lima, a Centro e a Água Branca. Existe uma quarta operação, que estamos revendo, a Operação Água Espraiada. Finalmente, há outras que estão sendo cogitadas: Vila Leopoldina, em torno da Ceagesp, Operação Tamanduateí, na Mooca, na realidade, na parte industrial, hoje pouco utilizada e a do Carandiru. Então, estamos por meio disto projetando corredores e áreas inteiras, a fim de poder propor a empresários e empreendedores privados uma parceria para a realização de obras e atividades.

Existem algumas operações urbanas de área menor, mas igualmente importantes como uma operação urbana na região do Butantã e na Vila Sônia destinadas a acoplar uma estação do Metrô da Linha 4 a uma estação rodoviária, recebendo os ônibus que circulam pela Raposo Tavares e pela Régis Bittencourt. Na mesma Linha 4 do Metrô, na outra ponta, existirá outra operação urbana provavelmente acoplada ao Projeto Monumenta, financiado pelo BID e pelo Ministério da Cultura, na região da Luz, incorporando a nova estação do Metrô a ser construída no seu subsolo. Portanto, haverá uma série de operaçōes urbanas; e para trabalhar por meio de operações urbanas, um dos instrumentos é a transferência do potencial construtivo.

MI: Ela não faz necessariamente parte da operação urbana?

JW: A essência da operação urbana não deve ser a transferência do potencial construtivo. A essência deve ser o redesenho de um setor da cidade. A maneira de dinamizar a realização disso muitas vezes utiliza diversos instrumentos financeiros, inclusive o da transferência de potencial construtivo. A transferência do potencial construtivo foi um instrumento criado quando era secretário do Planejamento do Covas e foi feito para tentar salvar os casarões da avenida Paulista que estavam sendo destruídos, aos domingos, embora estando tombados pelo patrimônio. Era tão chocante a impossibilidade de utilizar o potencial construtivo do terreno, altamente valorizado no mercado, que propusemos a transferência, retirada do valor construtivo, da capacidade ou coeficiente de aproveitamento do terreno, desligando-o fisicamente da área para poder ser aplicado em outras áreas da cidade. Isto hoje está sendo feito. Essa transferência é onerosa e tem dado bons resultados quando existe uma demanda de mercado grande como é o caso da Operação Faria Lima, que fornece recursos à 
prefeitura, aplicados na desapropriação e construção da avenida, a qual corresponde a uma diretriz viária correta. Fornece também recursos para serem aplicados na região em outras obras que possivelmente vão ser realizadas mais cedo ou mais tarde. $O$ instrumento parece bom para as parcerias, mas queremos que ele esteja sujeito a uma visão nova, de uma iniciativa da prefeitura, no sentido de realizar objetivos mais claros: o que fazer com esse bairro, com essa região. Assim, como exemplo, estamos tentando melhorar a Operação Água Branca que, embora tenha propiciado uma utilização de boa qualidade nos terrenos da antiga Indústria Matarazzo, parece-me ainda pobre, se comparado com o enorme potencial que a Água Branca possui, pois a área da operaçāo estende-se até a Marginal do Tietê.

JO: Sai a Linha 4: Taboão da Serra - Luz?

JW: Ela está viabilizada financeiramente. Estamos negociando com o Estado, pois a prefeitura tem outra estratégia, mas não há conflitos de interesses. São lógicas diferentes. O Estado está de acordo a discutir e nós, da prefeitura, estamos propondo como contribuição a construção de duas estações por meio de operações urbanas na Vila Sônia e na Estação da Luz. Implica essa utilização de instrumentos modernos, relativamente recentes em uma revisão da lei de zoneamento? Pretendemos rever a lei de zoneamento, sim! É um assunto delicado, porque é pelo zoneamento que se confere valor monetário à propriedade da terra. Por mais que se afirme que o uso do solo urbano deve estar subordinado à sua função social, traduzir essa posição doutrinária no dia-a-dia de uma cidade, especialmente, numa cidade como São Paulo, não é passivo, nem simples, nem foi descrito como é que se faz isso. Estamos todos de acordo, porém sem nenhuma conclusão prática. Temos que encontrar as formas de dar uma expressão real a essa doutrina, justa do ponto de vista ideológico. A revisão do zoneamento obedecerá a dois critérios: o desenvolvimento urbano, o que o plano diretor estabelece como diretriz genérica ao desenvolvimento da cidade latu-sensu. Em segundo lugar, o critério de ajuste dos direitos de vizinhança. Encontrar formas pela qual o interesse público, embora não seja sinônimo de interesse de todos, possa seguir por um caminho de menor resistência e maior apoio. A sociedade é plural e os interesses são conflitantes, embora sendo legítimos. Haver conflitos por diferença de interesses é algo que deve ser aceito, não de uma forma fatalista, mas como um dado real da sociedade. No entanto, o governo tem a obrigação de decidir, de determinar, em função do que se chama interesse público e deve arcar com os riscos dessa decisão. Por vezes um governo toma decisões, convicto de que está defendendo o interesse público e não tendo sequer o apoio da maioria. Esse é um risco político. A maioria da população, por muitas razões, inclusive subjetivas, de momento, pode não entender que determinada diretriz ou ação interessa à cidade. Por quê? Porque o interesse será revelado no longo e no médio prazo, mas a população vive o dia-a-dia. Seja lá como for, pode acontecer, (é melhor que não aconteça...), mas pode acontecer, que um governo, não só o municipal, tome decisões corretas e com grande convicção, não contando naquele momento com apoio da maioria. É assim, com essa visão e usando esses instrumentos, que procuramos trabalhar. Sempre buscando uma visão global, que nos obriga a ter uma visão metropolitana e a ter uma visão mundial do significado de São Paulo. Não podemos ter de São Paulo uma visão provinciana, pequena. Nossos espaços públicos sāo ainda pobres, escassos, raros. Somente as grandes capitais brasileiras - Salvador, Rio de Janeiro e Brasília tiveram o cuidado com o espaço público, por causa de sua função simbólica, pois eram capitais, sede do poder ostensivo.

São Paulo, que cresceu e se metropolizou no século 20, sofre de soluções mesquinhas e cometeu graves erros no passado. 0 primeiro grande erro foi não acreditar em Saturnino de Brito, na década de 20. Ocuparam-se as maiores 
várzeas, que pertenciam aos rios e não ao homem. $O$ segundo grande erro - que o engenheiro Prestes Maia, que certamente está no céu, me perdoe - foi feito por ele, quando achou, na década de 50 , que o sistema de grandes avenidas de fundo de vale significava um avanço e uma economia, pois se construía uma avenida e ao mesmo tempo canalização subterrânea do córrego que percorreria esses vales. Hoje nós sabemos, depois de décadas de impermeabilização da cidade, que esse foi um equívoco e que o fundo dos vales deveria ter sido reservado a parques lineares, de maneira a possibilitar a extravasão das águas de um córrego, assim como a captação das águas aquelas muitas vezes citadas: as cidades globais do livro da Saskya Sassen, ou do sistema de megacidades, das cidades com mais de 10 milhões de habitantes, citados por outros autores. Nós podemos, para fins de estudos e comparações, até elaborar essas classificações e proceder a estudos comparativos interessantes, mas não parece que seja essa a descrição mais fiel do que é a verdadeira situação urbana mundial. Eu a descrevo como um arquipélago de ilhas de consumo moderno, rodeadas por oceanos de exclusão. Há ilhas grandes em Londres, Nova York e ilhas de igual caráter, porém menores, em São Paulo e em Bombaim. Nelas moram pessoas que têm costumes semelhantes, hábitos de consumo moderno e que vivem no mesmo ritmo frenético alimentado pela conectividade global; falam a mesma língua, geralmente o inglês. Essas ilhas estão rodeadas de populações que estão excluídas desse ritmo e desse consumo. O oceano é pequeno em Nova York e Paris, porém não menos turbulento que os mares de Bombaim, em torno de São Paulo e de outras cidades mais pobres do que São Paulo. Minha visão da realidade urbana de hoje é desse arquipélago. Portanto, temos problemas, e problemas sérios, nas grandes cidades européias, cujos países perdem população e enfrentam uma imigração que será crescente, com todos os problemas de aculturação positiva, no longo prazo, mas cheia de tensões no curto prazo. Temos problemas nas cidades mais pobres como as grandes megacidades do século 21 que - além de Tóquio, São Paulo e México incluem Bombaim, Bangladesh, Karashi Daka, Lagos, como grandes megacidades com infraestrutura paupérrima, com o crescimento extremamente rápido e representando problemas gigantescos para a saúde pública.

MI: Essa é a questão sobre a qual me referi anteriormente, uma vez que são problemas que transcendem administrativamente a municipalidade.

JW: Mesmo quando transcendem não há como se omitir. É preciso iluminar as conexões entre o local 
e o global, entre o urgente e o importante. Para qualquer governo há sempre assuntos urgentes e assuntos importantes: não são sinônimos. Somos obrigados a atender problemas urgentes, como as chuvas de verão, por meio de programas de defesa civil, no momento. Mas temos de resolver assuntos importantes, como a drenagem em São Paulo. 0 problema da drenagem em São Paulo requer algumas leis que interrompam a impermeabilização e todo um trabalho por bacias a ser empreendido com outros municípios. Não vamos poder dar uma diretriz para as oportunidades que São Paulo oferece em sua economia, se não tivermos uma visão global do que significa a mudança dos paradigmas da produção industrial no mundo. A esse respeito defendo tese, já há muitos anos, que São Paulo vai passar por uma fase de reindustrialização. Isto não significa recuperação dos mesmos empregos, porque muitos deles estão definitivamente perdidos. Tampouco ocorrerá um grande aumento de emprego industrial. O que muda é o tipo de indústria. Esse novo tipo de indústria de São Paulo oferece oportunidades, que são claramente percebidas por grandes empresas internacionais, só que não sempre pelas autoridades federais, haja vista a inexistência de uma política de apoio às metrópoles. As empresas percebem claramente: São Paulo é um lugar de grande capacidade de adequação às tecnologias novas, é um lugar de mercado local imediato. São Paulo apresenta todas as oportunidades. Só não tinha até o presente momento a credibilidade de honestidade de propósitos. O malufismo causou, além de outros males, o da perda de credibilidade por causa da corrupção. O suficiente para que tanto bancos e entidades bilaterais, como outros países e empresas privadas colocassem a cidade de São Paulo como um grande ponto de interrogação, eventualmente, dando preferência na América do Sul a outras metrópoles. Restabelecida a credibilidade, há em São Paulo uma grande oportunidade de dar um salto para frente. Para isso é preciso pensar São Paulo na condição de sua real posição no mundo. Não podemos pensar pequeno. Temos que saltar etapas.

WJ: Quais os pontos críticos? Transportes?

JW: É realmente um problema crucial e vamos trabalhar nesse setor, mas não vamos resolver o problema do transporte público em 4 anos, pois precisamos construir $100 \mathrm{~km}$ de metrô. Nenhuma cidade consegue fazer mais que $10 \mathrm{~km}$ por ano, porque se trata de grandes obras embaixo dela. Enfim, $10 \mathrm{~km}$ por ano, durante 10 anos, significa que os $100 \mathrm{~km}$ que faltam para a rede dos $140 \mathrm{~km}$ do projeto original.

Mas a ação imediata, que a atual prefeitura pode fazer, é aquilo que já é sabido, é aquilo que sempre foi possível fazer, só não foi feito por falta de vontade política: fazerem os ônibus percorrer os seus trajetos dentro de um horário aceitável. Portanto, fazerem percorrer faixas e corredores exclusivos. Esta é a primeira tarefa que a Secretaria de Transportes está realizando a fim de poder dar ao transporte coletivo uma certa decência.

MI: Com que combustivel, já que circulam ônibus polventes e os atuais elétricos são trambolhos urbanos?

JW: Pois com eletricidade, sim! Mas não esse que está aqui. A tendência mais moderna, isso também eu tenho falado já há alguns anos, é de eletrificar todos os veículos por meio de pilha de hidrogênio: eletricidade gerada de forma nãopoluente, no próprio veículo.

MI: Isso vai levar tempo!

JW: Não! Não vai levar tempo, porque São Paulo já vai ter os primeiros ônibus a pilha de hidrogênio no ano que vem. Eles existem, estão sendo testados em Vancouver e Chicago. A EMTU do Estado já contratou seis deles e dentro da parceria com o Estado estamos solicitando que dois deles nos sejam cedidos para teste também... A pilha de hidrogênio pode fabricar hidrogênio a partir do álcool; há também outras maneiras de eletrificar o veículo colocando um sistema gerador dentro do ônibus, eletrificando a linha por trilho lateral que conduz um guia eletrônico enterrado no eixo de 
uma via. Tecnologias novas que estão sendo adotadas no mundo e em São Paulo não podem adotar nada a não ser o que estiver na ponta tecnológica. Temos condições de saltar etapas. Não só porque o merecemos, mas porque essa é uma despesa inteligente. Então, os corredores estão sendo pensados não só como faixa exclusiva, mas também considerando qual o veículo mais adequado.

A civilização ocidental está enfrentando um período de transição de sua história. Como tenho dito, há seis ou sete anos, não acredito que o momento atual seja um mero momento de ajuste da economia a uma tecnologia de comunicação que permite a comunicabilidade global. Esta criou o ambiente no qual vivemos, que é chamado de globalização. Acho que não se trata do mero ajuste. Há alguns ajustes sim, mas 0 aspecto mais rico em potencialidades reside nas rupturas que hoje ocorrem. Devemos ver o que há de criativo nas rupturas. Costumo dizer que a lâmpada elétrica não foi inventada pelo aperfeiçoamento da lamparina ou da vela de cera. Houve um salto, e não devemos temer dar saltos. Enfrentamos um futuro sem poder sequer dar nome a ele. Tanto que falamos em pós-capitalismo, pósindustrialização, pós-modernismo. Aquilo que vem depois, que ainda não tem nome, porque não existe sequer o conceito. Isto faz com que vivamos em um momento de grande ansiedade, de angústia, mas também de enorme possibilidade de criação. Neste sentido, a participação de toda a intelectualidade e a necessidade de redefinir 0 futuro faz com que todos aqueles que pensam, que criam os centros de pesquisas, as universidades, todos se transformem em enciclopedistas do século novo. Assim como vivemos em período de renegociação do pacto social, também vivemos um período de redefinição do cosmo do mundo, do futuro.

WJ: No caso da Faculdade de Arquitetura e Urbanismo, que pesquisas, que temas você colocaria para trazer à tona essa nova criaçāo diante da crise?
JW: Necessita-se de conhecimentos por processos capazes de integrar diferentes perspectivas científicas. A era da comunicação na qual estamos vivendo nos coloca uma grande ampliação do mundo da informação. Mas informação ainda não é conhecimento. A internet nos fornece dados e informações das quais eventualmente podemos tirar o conhecimento necessário. E conhecimento ainda não significa sabedoria... Acredito que este será um dos grandes desafios da educação: transformar informação em conhecimento. Isso se fará em um futuro próximo, por métodos que provavelmente serão diversos dos que têm sido usados até hoje. Onde cabe a intuição na aquisição do conhecimento? Onde cabe o diálogo interdisciplinar, absolutamente necessário na obtenção do conhecimento? Vivemos hoje numa época em que os filhos, em alguns aspectos, realmente sabem mais que os pais e alguns alunos sabem mais que os professores. São desafios metodológicos e filosóficos no campo da educação, do ensino. Não há a menor dúvida que se deve buscar o conhecimento pelas práticas interdisciplinares. Isso não deve ser entendido como abandono do cientista que pesquisa uma bactéria ou o núcleo de um átomo e que faz disso a sua vida. Porque também precisamos desse tipo de especialidade: ele vai alimentar um determinado esquema ou estrutura de obtenção de conhecimento mais geral. E fará descobertas. No caso das faculdades de arquitetura, que lidam com espaços a serem construidos, seja no projeto de uma casa, seja na estruturação de uma cidade, temos desafios imediatos muito típicos. Vivemos num país que tem no oeste uma fronteira móvel. São pouquíssimos os países que ainda têm fronteiras internas móveis. Enquanto aqui em São Paulo conversamos, alguma cidade está nascendo ao longo da rodovia em Roraima. Nós não investigamos o suficiente, nem desenvolvemos na urbanística brasileira o conhecimento do que significa cidade pioneira, como ela se desenvolveu planejadamente, como ela deve ser desenvolvida. Quando tive experiência na 
década de 50 , de projetar uma cidade nova, não tinha para onde me voltar, socorri-me lendo $A$ urbanística moderna européia, um livro do geógrafo francês Pierre Monbeig, que tinha estudado as cidades novas do estado de São Paulo, em que aprendi muitíssimo para poder fazer a ponte entre Le Corbiesier e a realidade de uma cidade qualquer do Oeste Paulista. Temos um vasto campo de estudo, até olhando para trás a fim de haurir lições.

Por outro lado, há desafios novos: o que significa zoneamento flexível? O que significa lidar com parcerias? O que significa paisagem urbana, o que caracteriza a paisagem, os lugares e os espaços como entidades que são diferentes? O que significa economia solidária, que não foi ainda desenvolvida, desde as cooperativas, a reencenação da autogestão tentada na década de 70 e depois abandonada? Há um mundo de coisas a serem estudadas. É preciso também ler tudo o que está sendo publicado.

MI: Há uma grande produção de teses nãopublicadas.

JW: É preciso conhecer melhor a dinâmica geradora da cidade brasileira. Estudar a cidade ilegal. Os intelectuais brasileiros estão produzindo livros e artigos realmente interessantes. Porém, há pouca literatura científica brasileira sobre urbanismo. Há teses interessantes que estão sendo publicadas, mas é preciso saber ler inglês... O nosso atraso no conhecimento de línguas viciou muito as escolas de arquitetura. Na verdade, lia-se aquilo que era publicado em espanhol; às vezes, em italiano, embora Argan não seja um autor fácil de ser lido para quem não conhece o italiano: esperava-se sempre que fosse traduzido. Mas o que foi publicado em inglês foi ignorado. Jane Jacobs é pouco conhecida aqui, embora ela tenha escrito uns dez livros e alguns deles abriram pioneiramente uma perspectiva muito interessante para o urbanismo. Agora lemos em português: lembro que foram escritos há 20 anos. Houve um certo atraso no conhecimento do que é feito no mundo. Hoje se traduz muito, o movimento editorial é grande no Brasil... Mas livros assim de arquitetura não são best-seller, embora tenhamos muitas faculdades de arquitetura hoje no Brasil. A massa leitora, desde que incentivada pelos mestres, pelos professores, até que não é pequena.

Bem, creio que respondi às perguntas que me fizeram... 